\title{
GraphDNA: a Java program for graphical display of DNA composition analyses
}

\author{
Jamie M Thomas, Daniel Horspool, Gordon Brown, Vasily Tcherepanov and \\ Chris Upton*
}

Address: Department of Microbiology and Biochemistry, University of Victoria, Victoria, BC, V8W 3P6, Canada

Email: Jamie M Thomas - jmthomas@uvic.ca; Daniel Horspool - dhorspool@gmail.com; Gordon Brown - gdbrown@uvic.ca; Vasily Tcherepanov - vasilyt@uvic.ca; Chris Upton* - cupton@uvic.ca

* Corresponding author

Published: 23 January 2007

BMC Bioinformatics 2007, 8:21 doi:| 0.| |86/|47|-2105-8-2|
Received: 02 June 2006

Accepted: 23 January 2007

This article is available from: http://www.biomedcentral.com/I47I-2/05/8/2I

(c) 2007 Thomas et al; licensee BioMed Central Ltd.

This is an Open Access article distributed under the terms of the Creative Commons Attribution License (http://creativecommons.org/licenses/by/2.0), which permits unrestricted use, distribution, and reproduction in any medium, provided the original work is properly cited.

\begin{abstract}
Background: Under conditions of no strand bias the number of Gs is equal to that of Cs for each DNA strand; similarly, the total number of Ts is equal to that of As. However, within each strand there are considerable local deviations from the $A=T$ and $G=C$ equality. These asymmetries in nucleotide composition have been extensively analyzed in prokaryotic and eukaryotic genomes and related to chromosome organization, transcription orientation and other processes in certain organisms. To carry out analysis of intra-strand nucleotide distribution several graphical methods have been developed.

Results: GraphDNA is a new Java application that provides a simple, user-friendly interface for the visualization of DNA nucleotide composition. The program accepts GenBank, EMBL and FASTA files as an input, and it displays multiple DNA nucleotide composition graphs (skews and walks) in a single window to allow direct comparisons between the sequences. We illustrate the use of DNA skews for characterization of poxvirus and coronavirus genomes.

Conclusion: GraphDNA is a platform-independent, Open Source, tool for the analysis of nucleotide trends in DNA sequences. Multiple sequence formats can be read and multiple sequences may be plotted in a single results window.
\end{abstract}

\section{Background}

The nucleotide composition of genomic DNA is very variable. This variation is not limited to non-coding DNA or influencing codon-usage, it also results in changes to the amino acid composition of proteins. For example, the redundancy of the genetic code does not completely buffer the amino acid composition of orthologous proteins from Vaccinia virus (VACV; an Orthopoxvirus; 65\% $\mathrm{A}+\mathrm{T}$ ) and Molluscum contagiosum virus (MOCV; a Molluscipoxvirus; 35\% $\mathrm{A}+\mathrm{T}$ ). The amino acid composition of the DNA polymerases of VACV and MOCV illustrate that the propensity for certain amino acids to be more common in proteins encoded by $\mathrm{A}+\mathrm{T}$ or $\mathrm{G}+\mathrm{C}$ rich genes; the VACV and MOCV proteins contain the following percentages of lysine $(7.1,2.9)$, arginine $(5.9,9.6)$, alanine (4.0, $9.5)$, leucine $(9.3,12.2)$ and isoleucine $(7.4,3.2)$, respectively.

There is also considerable variation in DNA composition within a genome. Regions rich in repeated DNA often 
have a nucleotide composition quite different to the genome average. Similarly, all poxvirus promoters are very $A+T$ rich regardless of the average genome nucleotide composition. However, it is less well appreciated that there is also a wide variation in the DNA composition of individual genes, the $\mathrm{A}+\mathrm{T} \%$ range for individual genes in VACV and MOCV is $55.1-72.3$ and $24.0-51.8$, respectively. The driving force for divergence in DNA composition among evolutionary related poxviruses is unknown, as is the ancestral composition, but range of DNA composition among genes is determined by at least 2 components: 1) the natural resistance of some genes to change because of restrictive amino acid requirements, and 2) the acquisition of novel genes after speciation of the viruses.

Other processes related to DNA replication, repair and transcription may also influence nucleotide biases of the two DNA strands [1-5]. For example, since the coding strand of bacterial genomic DNA tends to be purine rich [6] and majority of genes are transcribed in the same direction as the movement of the replication fork there is asymmetric nucleotide composition along the genome such that the DNA composition may be used to predict the origin and termini of replication [7-9].

Genomic variations in nucleotide composition have been successfully studied using several graph-based methods. One such technique is to draw a cumulative skew diagram, which plots the relative amounts of two nucleotides in a given DNA sequence [10]. A GC skew, for example, is calculated across a genome as the sum of a series of sliding windows of specified length; the window size can be 1 or much larger for a complete genome. The shape of the resulting cumulative dinucleotide curves have been correlated with important sequence features including viral origins of replication [11] and genome rearrangements in bacteria [12]. The "DNA walk" is another method used to study nucleotide distribution, first described by Lobry $[7,13]$ and used to detect origins of DNA replication in bacteria genomes. To graph a DNA walk, a direction (North, South, East, and West) is assigned to each of the four nucleotides and the sequence is then plotted on a graph, beginning at $(0,0)$ and moving one step in the direction specified by each successive nucleotide.

This paper describes GraphDNA, a new Java software application, that was developed as a platform-independent application to present DNA skews and walks of multiple sequences in a single graph and thus assist in the comparative analysis of nucleotide composition asymmetry.

\section{Implementation}

To support cross-platform utility, GraphDNA was developed as a Java application. Users initially access and launch the application from a web page using Java Web Start, which also automatically downloads updated versions of the program as they become available. This ensures users are taking advantage of improvements or added features in the latest software versions.

GraphDNA can read DNA sequences from several sources. First, this input can consist of a single file containing one or more DNA sequences or a series of separate sequence files can be loaded; the nucleotide sequence data may be in FASTA, EMBL or GenBank formats. Second, the application can connect to our VOCs database at the Viral Bioinformatics Resource Centre (VBRC) [14] that stores the complete genomes from more than 10 families of viruses; in this case, GraphDNA also receives the gene annotations for the genomes. GraphDNA has been successfully tested with a $20 \mathrm{Mb}$ DNA sequence and can therefore handle all currently sequenced viral and bacterial genomes.

The time required by GraphDNA to load DNA sequences and display plots is dependent upon the size and number of sequences as well as the nucleotide window size used for calculating skews and walks. The time to load and display a GC skew for 4 poxvirus genomes (average size 200 $\mathrm{Kb}$ ) was approximately $40 \mathrm{~s}$ with a default window size of 1 nucleotide; however, replotting the same data with a window size of 10 nucleotides took $<5 \mathrm{~s}$ ( $2 \mathrm{GHz}$ dual processor). When large ( $>200 \mathrm{~Kb})$ DNA sequences are loaded, the program automatically selects a window size of 70 nucleotides and permits the user to change that window size, this reduces the processing and display times; for example, the time required for loading and plotting the GC skews of two $20 \mathrm{Mb}$ DNA sequences was approximately 2 minutes on a dual $2 \mathrm{GHz}$ desktop computer; replotting this data with another nucleotide skew took $<45$ s.

Additional features include: 1) the application can accept gapped multiple alignment files in FASTA format; this permits homologous regions of genomes to be kept in register and allows easier comparison of skews among several sequences. Horizontal lines are drawn at gapped positions; this reflects no change in nucleotide skew, but an increase in nucleotide count; 2) gene annotations are displayed underneath the main window if they have been loaded with the DNA sequences (transcript direction is shown and the gene name is also displayed when space permits), if multiple sequences have annotations, a menu allows the user to choose which annotations to display; 3 ) it is possible to zoom into regions of the plots (a selection is made by holding down the left mouse-button and dragging across the region), both the plot and the genome annotation displays are affected by this procedure and clicking the "Recenter button" switches back to the full genome view. 
GraphDNA allows plots to be saved as PNG formatted files (save as, under File menu), the best resolution is obtained if the application window is stretched to its maximum size before saving; alternatively, screen images can be captured.

\section{Algorithms}

In a "DNA walk" graph, sequences are plotted starting at $\mathrm{X}=0, \mathrm{Y}=0$. For each nucleotide (from position 1 in the sequence to the end), the position of the next point in the plot is calculated relative to the current position: for nucleotide $\mathrm{C}, \mathrm{G}$, T or $\mathrm{A}$, the position moves north, south, east or west, respectively. If the current symbol is degenerate or a gap symbol, the position is unchanged. For a window size of $k$, every k'th point is actually drawn on the graph (but the calculations still include every nucleotide). A slider bar moves markers along the plots to locate specific regions of the sequences since the position of a particular nucleotide is solely dependent on the composition of the preceding nucleotide sequence, not on the position in the sequence.

Purine skews are calculated from the first position in the sequence to the last: for each nucleotide, increment a counter if this nucleotide is a purine; decrement it if it is a pyrimidine. The effect is to compute the number of purines minus the number of pyrimidines from the first position to the current one. The X-axis of the skew graph is the position in the sequence; the Y-axis is the value of the counter at this position. Keto and dinucleotide skews are calculated analogously, with the obvious differences. For a window size of $k$, every k'th position is drawn.

\section{Comparison to other programs}

Several other programs have been written to display DNA strand composition asymmetries. DNASkew [15] is a Perl script limited to a command line interface; GenSkew [16] and Artemis [17] are Java applications, but are limited to certain nucleotide skews and cannot plot multiple sequences; Genometrician's Scooter ${ }^{\mathrm{TM}}$ [18] is able to perform DNA walks and skews, but is not Open Source or platform independent. GraphDNA was written to overcome these limitations and also to be compatible with the VOCs database [19] for access to viral genomes.

\section{Results and discussion}

The GraphDNA application has three basic graphing functions: DNA walks, cumulative dinucleotide skews and cumulative purine/keto skews. The DNA walk analysis is most effective when nucleotide composition trends extend over a considerable length. For example, DNA walks have been successful in finding the origins and termini of replication in bacterial genomes $[7,20]$.
An example of cumulative purine/keto skews is shown in Figure 1, which demonstrates that different regions of the ectromelia virus, an orthopoxvirus, genome have considerably different purine content. It was observed that the "W" shape of the purine skew (Figures 1A and 1B) was very similar to the pattern for transcriptional orientation of the viral genes along the linear genome (Figure 1C). Examination of the genes from multiple orthopoxviruses confirmed that the coding strand of poxvirus genes tends to be slightly purine rich [21]. This information can be used to help annotate novel genes in poxvirus genomes in that if there are small ORFs on both DNA strands, then the strand with the highest purine content is most likely to be the coding strand; however, purine content is only one of a variety of information sources used in the annotation process [22]. Cumulative skew analysis may also be pertinent to some eukaryotic DNA sequences; for example, the coding strand of Leishmania major strain Friedlin chromosome 1 [23] is associated with an excess of pyrimidines.

The cumulative dinucleotide skews display the abundance of one nucleotide relative to another across the length of a DNA sequence that may represent a single gene or a complete genome. The program plots the cumulative dinucleotide counts calculated in a series of "windows", which may be as small as $1 \mathrm{nt}$, along the DNA sequences; GraphDNA offers all six possible cumulative skews (GC, AC, GT, TC, AG and AT). GC and AT skews have been widely used to predict termini and origins of replication in bacterial $[1,9]$ and mammalian genomes [8], transcription start sites in plants and fungi [24], as well as transcription regions in the human genome [25]. In poxviruses, some skews, for example the GA skew, appear to be independent of the orientation of transcription, and instead reflect the overall nucleotide composition of the genome (Figure 2). However, when genomes are examined in more detail, heterogeneities can be observed. The GA skew of the $16-38 \mathrm{~Kb}$ region of the crocodilepox virus genome from Figure 2 is displayed in Figure 3. Genes $28,29,30,31,33,34$ and 35 appear to make up an island of unusual skew. This is interesting because genes 28, 33, 34 and 35 are distantly related and probably arose from ancient duplication events. Of all the genes in the region 28 - 35, only gene 30 has any similarity to other known proteins; it is similar to DNAJ-like molecular chaperones and has an ortholog in MOCV, another GC rich poxvirus. The unusual overall base composition of this region may be the result of incorporation of foreign DNA into an ancestral crocodilepox virus genome. It is likely that this was through multiple events and an early smaller DNA island may have served as an integration site for subsequent insertions.

Since the above analysis of crocodilepox genes indicated that DNA composition signature can reflect evolutionary 
A

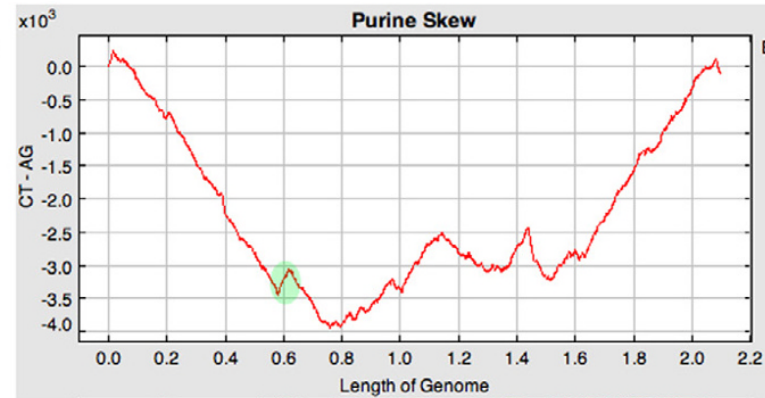
ECTV-Mos =

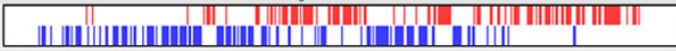

$\mathrm{x} 10^{5}$

View Genes for Genome: ECTV-Mos $\vdots$

B

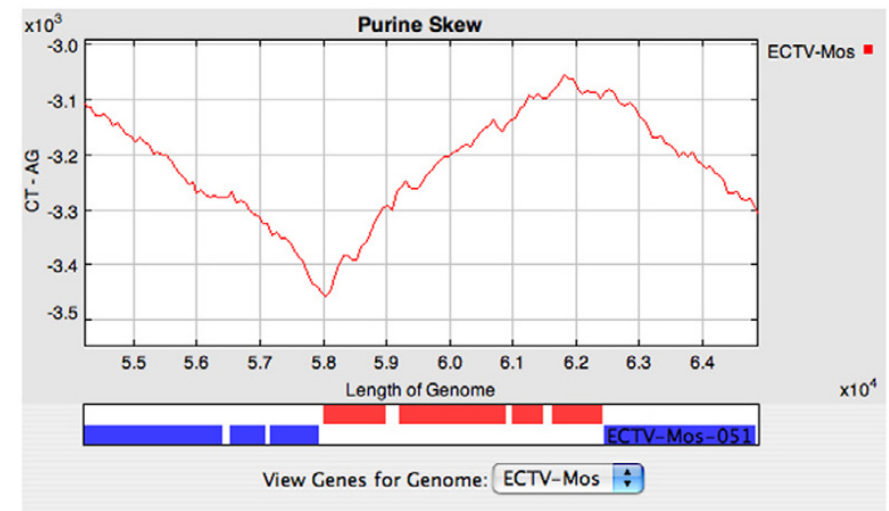

C

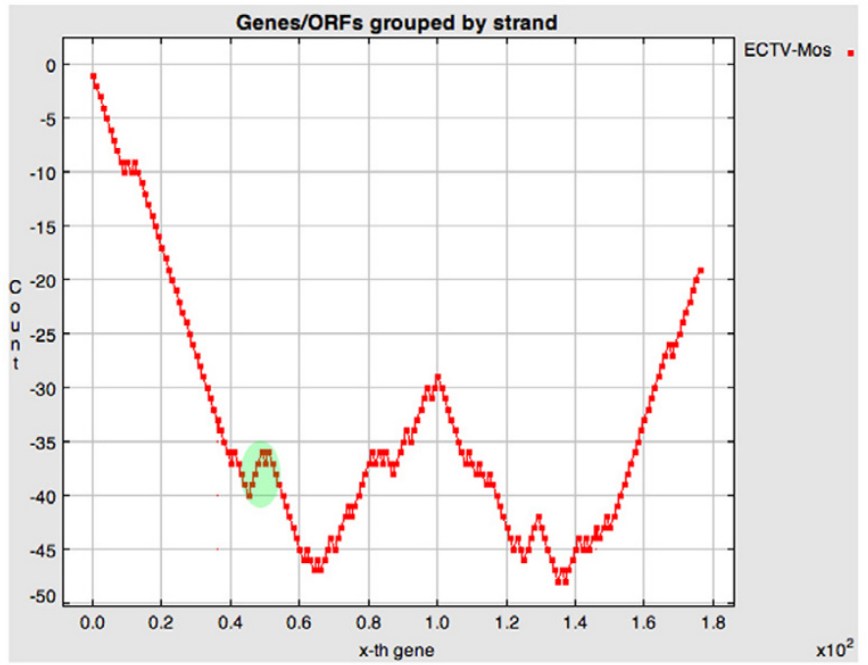

Figure I

Panel A: Purine skew for the complete genome of Ectromelia virus strain Moscow (NC_004I05.I). Gene annotations for this genome are show below the skew plot; genes are shown as red and blue bars to illustrate transcription towards the left and right ends of the genome, respectively. Green highlight shows 4 genes that are transcribed rightwards, which are flanked by genes transcribed leftwards. Panel B: Purine skew for the region highlighted in Panel A. Panel C: Plot of transcription orientation for Ectromelia virus genes. For genes transcribed to the left and right, the plot moves down and up, respectively. Green highlight as in Panel A. 


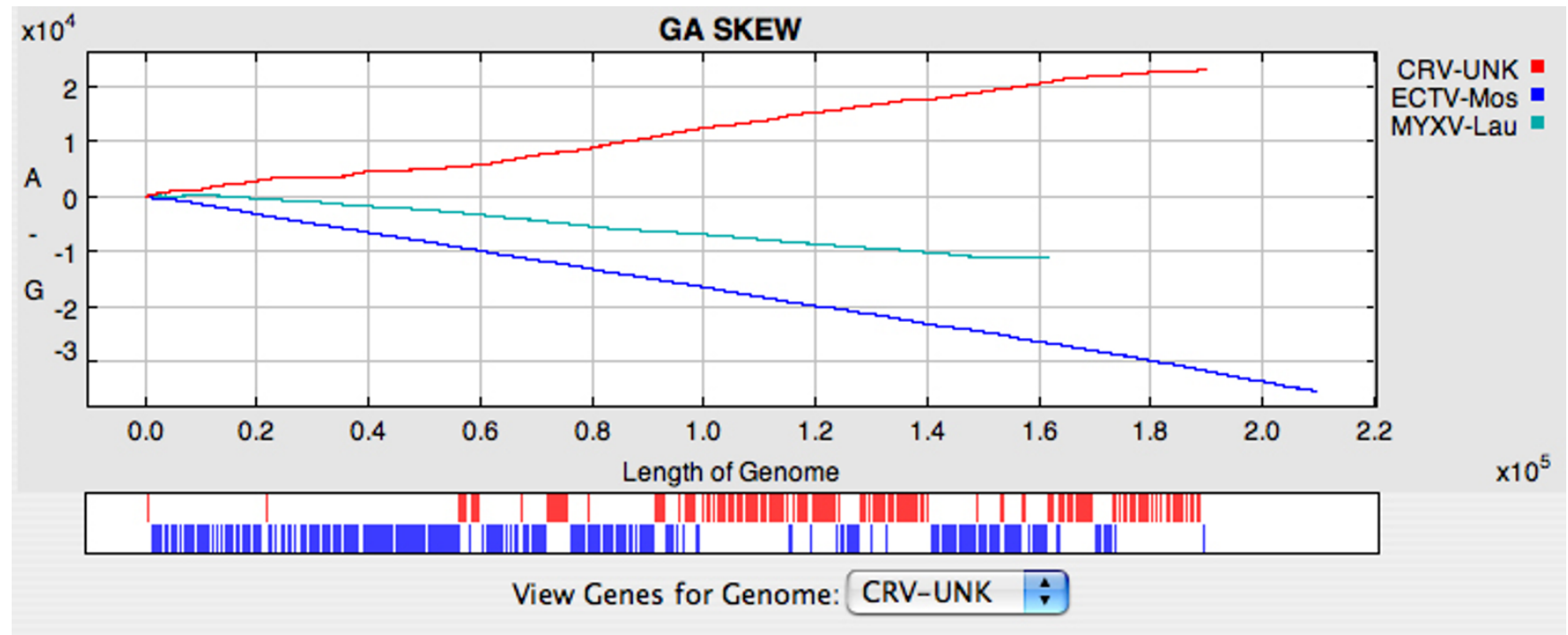

\section{Figure 2}

GA skews for the complete genomes of Ectromelia virus strain Moscow (NC_004I05.I), Crocodilepox virus (NC_008030) and Myxoma virus (NC_00I 132.2); the genome sizes range from 160 to $210 \mathrm{~Kb}$. Gene positions and transcription direction (red - rightwards; blue - leftwards) are shown in a box underneath the plots; if space permits, gene names are also displayed. A View Genes for Genome menu is provided to allow the user to select between multiple genomes.

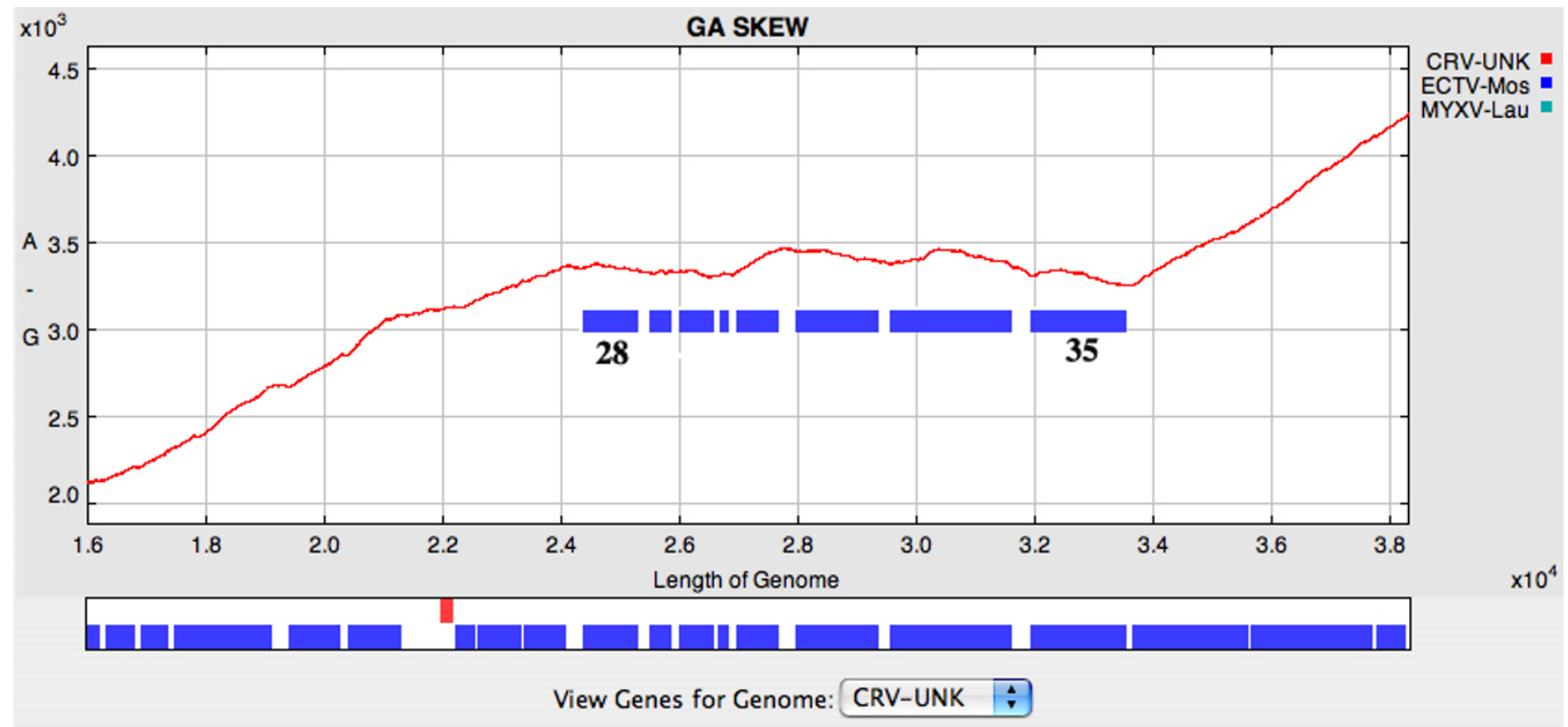

\section{Figure 3}

GA skew for the region $16-38 \mathrm{~Kb}$ of the Crocodilepox virus genome shown in Figure 2; note the change in scale shown. Blue bars on the plot represent genes $28,29,30,31,32,33,34$ and 35. 
A

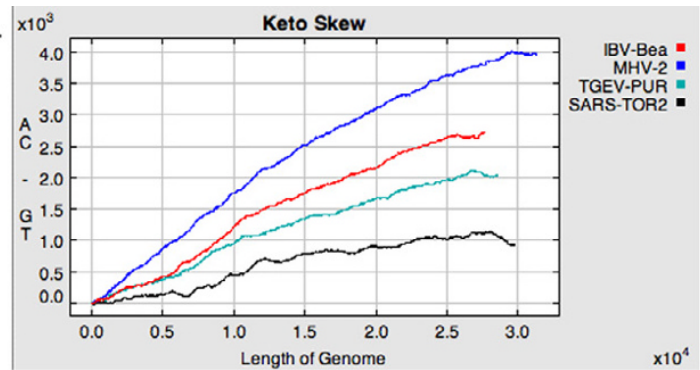

B

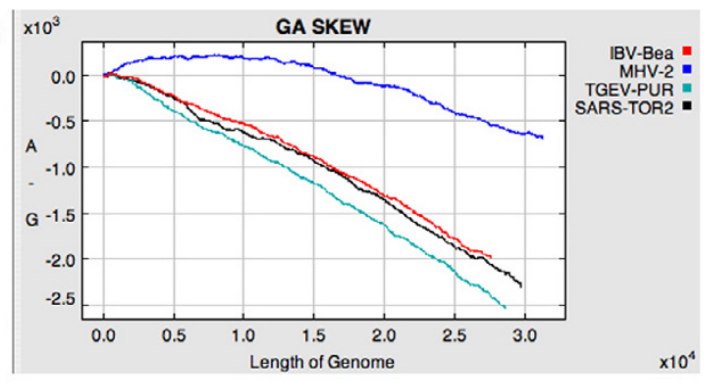

C $\times 10^{3}$

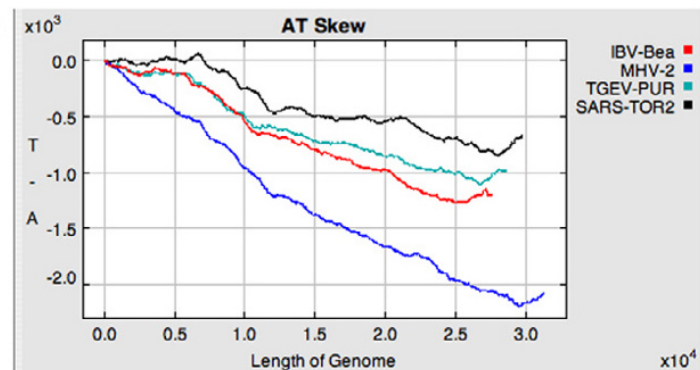

D $\mid \times 10^{\circ}$

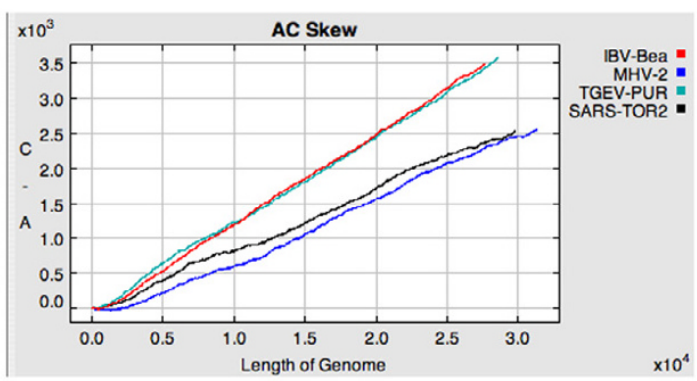

E

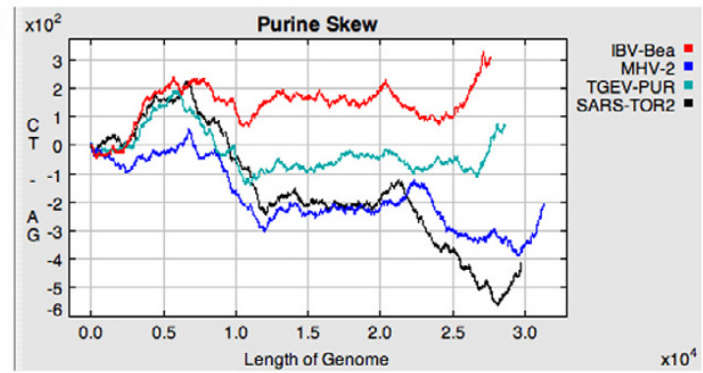

\section{Figure 4}

Panels A, B, C, D and E show keto, GA, AT, AC and purine skews for Transmissible gastroenteritis virus strain Purdue (Group I; NC_002306), Murine hepatitis virus strain 2 (Group 2; AF201929), Avian infectious bronchitis virus strain Beaudette (Group 3; NC_00I45I) and SARS coronavirus strain Tor2 (NC_0047I8), respectively. 
history even when protein sequences have diverged so far that reliable alignments are very difficult to generate and are limited to a very few essential amino acids (alignment of crocodilepox genes 28, 33, 34 and 35, results not shown), we looked at the relationship of SARS-coronavirus to other coronaviruses using nucleotide skews. When the SARS-coronavirus was first sequenced, it was reported that this novel virus was similarly and very distantly related to the three previously known groups of coronaviruses [26]. Subsequently, it was reported that SARS-coronavirus is slightly closer to the Group 2 coronaviruses $[27,28]$ and that it probably arose through a series of recombination events [29]. However, an examination of composition skews revealed that for most skews SARScoronavirus and mouse hepatitis virus (MHV), a Group 2 coronavirus are the most different; for example, see the keto, GA and AT skews in Figure 4A, 4B and 4C, respectively. Only the AC skews are most similar for SARS-coronavirus and the Group 2 MHV (Figure 4D). Several skews, and especially the purine skew (Figure 4E) indicate that the SARS-coronavirus genome is the most variable with regard to consistency of nucleotide composition across the genome. This is consistent with the ancient recombination events among ancestral coronaviruses proposed by Zhang et al. [29] after employing a battery of BLAST searches and 7 recombination detection techniques. Others have also examined nucleotide skews of coronaviruses, but this has been limited to GC skews [30,31] that show a depletion of cytosine relative to guanosine in the $10 \mathrm{~Kb}$ at the 3 ' end of the SARS-coronavirus genome. Both Grigoriev [30] and Pyrc et al. [31] suggested that this resulted from the unusual transcription process of the coronaviruses, but differed in their detailed models.

\section{Conclusion}

GraphDNA is an easy to use Java Web Start application designed to display and compare DNA sequences graphically using three available methods - DNA walks, cumulative purine/keto skews and cumulative dinucleotide skews. Although others have used nucleotide skews to analyze genomes and have predicted coding strand selection, replication origin and termini sites $[32,33]$, the tools to perform these analyses have not been readily accessible by the general research community. In contrast, GraphDNA is freely accessible via the Internet and runs on most computer platforms; in addition the source code is available through an Open Source license. GraphDNA offers a quick and easy method to compare the nucleotide skews of genomes and provides an additional analysis tool that is especially useful for characterization of distantly related nucleotide sequences.

\section{Availability and requirements Project Name: GraphDNA}

Project Home Page: GraphDNA may be accessed from the workbench at http://www.virology.ca/

Operating Systems: All platforms supporting Sun's JRE version 1.4 .1 or compatible

\section{Programming Languages: Java, SQL}

Other requirements: Java 1.4 or higher

License: Open Software License http://www.open source.org

\section{Authors' contributions}

JMT designed the interface and coded the prototype; DH and GB coded the final application; VT and CU described and specified the features of GraphDNA, tested the application, provided usage examples and wrote the manuscript. All authors read and approved the final manuscript.

\section{Acknowledgements}

This work was funded by NIAID grant HHSN266200400036C and Canadian NSERC Strategic Grant STPGP 269665-03. The authors thank Aijaz Syed for bug fixes.

\section{References}

I. Mrazek J, Karlin S: Strand compositional asymmetry in bacterial and large viral genomes. Proc Natl Acad Sci U S A 1998, 95(7):3720-3725.

2. Niu DK, Lin K, Zhang DY: Strand compositional asymmetries of nuclear DNA in eukaryotes. J Mol Evol 2003, 57(3):325-334.

3. Francino MP, Ochman H: Strand asymmetries in DNA evolution. Trends Genet 1997, 13(6):240-245.

4. Rocha EP, Danchin A: Ongoing evolution of strand composition in bacterial genomes. Mol Biol Evol 200I, 18(9):1789-1799.

5. Lopez P, Philippe H: Composition strand asymmetries in prokaryotic genomes: mutational bias and biased gene orientation. C R Acad Sci III 200I, 324(3):20I-208.

6. Lobry JR: Asymmetric substitution patterns in the two DNA strands of bacteria. Mol Biol Evol 1996, I3(5):660-665.

7. Lobry JR: A simple vectorial representation of DNA sequences for the detection of replication origins in bacteria. Biochimie 1996, 78(5):323-326.

8. Touchon M, Nicolay S, Audit B, Brodie of Brodie EB, d'AubentonCarafa $Y$, Arneodo A, Thermes C: Replication-associated strand asymmetries in mammalian genomes: toward detection of replication origins. Proc Natl Acad Sci U S A 2005, 102(28):9836-984I.

9. Kunst F, Ogasawara N, Moszer I, Albertini AM, Alloni G, Azevedo V, Bertero MG, Bessieres P, Bolotin A, Borchert S, Borriss R, Boursier L, Brans A, Braun M, Brignell SC, Bron S, Brouillet S, Bruschi CV, Caldwell B, Capuano V, Carter NM, Choi SK, Codani JJ, Connerton IF, Danchin A, et al.: The complete genome sequence of the gram-positive bacterium Bacillus subtilis. Nature 1997, 390(6657):249-256.

10. Grigoriev A: Analyzing genomes with cumulative skew diagrams. Nucleic Acids Res 1998, 26( I 0):2286-2290.

II. Grigoriev A: Strand-specific compositional asymmetries in double-stranded DNA viruses. Virus Res 1999, 60(1): I-19.

12. Grigoriev A: Graphical genome comparison: rearrangements and replication origin of Helicobacter pylori. Trends Genet 2000, I6(9):376-378

13. Lobry JR: Genomic Landscapes . Microbiology Today 1999, 26:164-165.

14. Upton C: Viral Bioinformatics Resource Centre. [http:// www.virology.ca]. 
15. Ma XR, Xiao SB, Guo AZ, Lv JQ, Chen HC: DNAskew: statistical analysis of base compositional asymmetry and prediction of replication boundaries in the genome sequences. Acta Biochim Biophys Sin (Shanghai) 2004, 36(I):16-20.

16. GenSkew [http://mips.gsf.de/services/analysis/genskew]

17. Rutherford K, Parkhill J, Crook J, Horsnell T, Rice P, Rajandream MA, Barrell B: Artemis: sequence visualization and annotation. Bioinformatics 2000, I6(10):944-945

18. Genometrician's Scooter ${ }^{\mathrm{TM}}$.

19. Ehlers A, Osborne J, Slack S, Roper RL, Upton C: Poxvirus Orthologous Clusters (POCs). Bioinformatics 2002, I 8(II): 1544- I545.

20. Roten CA, Gamba P, Barblan JL, Karamata D: Comparative Genometrics (CG): a database dedicated to biometric comparisons of whole genomes. Nucleic Acids Res 2002, 30(I): 142-144.

21. Da Silva M, Upton C: Using purine skews to predict genes in AT-rich poxviruses. BMC Genomics 2005, 6(I):22.

22. Upton $C$ : Screening predicted coding regions in poxvirus genomes. Virus Genes 2000, 20(2):159-164.

23. Myler PJ, Audleman L, deVos T, Hixson G, Kiser P, Lemley C, Magness C, Rickel E, Sisk E, Sunkin S, Swartzell S, Westlake T, Bastien P, Fu G, Ivens A, Stuart K: Leishmania major Friedlin chromosome I has an unusual distribution of protein-coding genes. Proc Natl Acad Sci U S A 1999, 96(6):2902-2906.

24. Fujimori S, Washio T, Tomita M: GC-compositional strand bias around transcription start sites in plants and fungi. $B M C$ Genomics 2005, 6(I):26.

25. Touchon M, Nicolay S, Arneodo A, d'Aubenton-Carafa Y, Thermes C: Transcription-coupled TA and GC strand asymmetries in the human genome. FEBS Lett 2003, 555(3):579-582.

26. Marra MA, Jones SJ, Astell CR, Holt RA, Brooks-Wilson A, Butterfield YS, Khattra J, Asano JK, Barber SA, Chan SY, Cloutier A, Coughlin SM, Freeman D, Girn N, Griffith OL, Leach SR, Mayo M, McDonald H, Montgomery SB, Pandoh PK, Petrescu AS, Robertson AG, Schein JE, Siddiqui A, Smailus DE, Stott JM, Yang GS, Plummer F, Andonov A, Artsob H, Bastien N, Bernard K, Booth TF, Bowness D, Czub M, Drebot M, Fernando L, Flick R, Garbutt M, Gray M, Grolla A, Jones S, Feldmann H, Meyers A, Kabani A, Li Y, Normand S, Stroher U, Tipples GA, Tyler S, Vogrig R, Ward D, Watson B, Brunham RC, Krajden M, Petric M, Skowronski DM, Upton C, Roper RL: The Genome sequence of the SARS-associated coronavirus. Science 2003, 300(5624): 1399-| 404.

27. Gorbalenya AE, Snijder EJ, Spaan W]: Severe acute respiratory syndrome coronavirus phylogeny: toward consensus. J Virol 2004, 78(I 5):7863-7866.

28. Eickmann M, Becker S, Klenk HD, Doerr HW, Stadler K, Censini S, Guidotti S, Masignani V, Scarselli M, Mora M, Donati C, Han JH, Song HC, Abrignani S, Covacci A, Rappuoli R: Phylogeny of the SARS coronavirus. Science 2003, 302(5650): I504-I505.

29. Zhang XW, Yap YL, Danchin A: Testing the hypothesis of a recombinant origin of the SARS-associated coronavirus. Arch Virol 2005, 150(I): I-20.

30. Grigoriev A: Mutational patterns correlate with genome organization in SARS and other coronaviruses. Trends Genet 2004, 20(3): 131-135.

31. Pyrc K, Jebbink MF, Berkhout B, van der Hoek L: Genome structure and transcriptional regulation of human coronavirus NL63. Virol / 2004, I:7.

32. Freeman JM, Plasterer TN, Smith TF, Mohr SC: Patterns of Genome Organization in Bacteria. Science 1998, 279(5358): 1827a.

33. Grigoriev, Andrei, Freeman JM, Plasterer TN, Smith TF, Mohr, C. S: Genome Arithmetic. Science 1998, 28 I(5385): 1923a.
Publish with Bio Med Central and every scientist can read your work free of charge

"BioMed Central will be the most significant development for disseminating the results of biomedical research in our lifetime. "

Sir Paul Nurse, Cancer Research UK

Your research papers will be:

- available free of charge to the entire biomedical community

- peer reviewed and published immediately upon acceptance

- cited in PubMed and archived on PubMed Central

- yours - you keep the copyright
BioMedcentral 